\title{
Notas sobre Pedro Henríquez Ureña
}

L estimé tanto que no podría ser apasionado ni unilateral. 1 Disto, pues, del coro de ditirambos incondicionales, y me siento más a mi placer en aquel puesto que él hubiera querido siempre ocupar: contemplador interesado, cosa distinta a ése que, según Ortega, "se inmuniza de lo contemplado". Además, Pedro posee materia suficiente para resistir pellizcos, golpes y dentelladas. A cincel puro se le puede reformar, es decir, presentar bajo forma distinta de la que por lo común se usa para dárnoslo por sabido.

El contacto directo que nos unió no fue como el largo e indirecto que mantuvimos por correspondencia desde más o menos 1925, yo estudiante aún. Comenzó en los primeros días de 1937. Pedro había asistido a la primera Escuela de Verano de la Universidad de Chile. Un hijo mío sufrió entonces serio accidente. La noche tétrica de la definición, Pedro estuvo a mi lado con una ternura increíble. Durante muchas horas se negó a dejarme con mi ansiedad. Desde luego, conversando de temas gratos e intensos. Me parece que también estuvo Amado Alonso, o fue al año siguiente esta nueva visita. Guardo de ello el recuerdo más agradecido y firme.

Ya habíamos estado juntos, en Buenos Aires, hacia septiembre de 1936. Nos reunió el PEN Club. Nos acercó la afición editorial, a que yo estaba entregado en aquel entonces. Una noche, nos juntamos en casa de la señora Gonet de Rinaldini, quien presidía unas reuniones socráticas. La noche de 
mi referencia asistieron Alfonso Reyes, Jorge Luis Borges y Pedro. En una pieza vecina discutían los planes de una futura revista un grupo de jóvenes discípulos. Estoy seguro de que uno de ellos era Enrique Anderson Imbert.

Después coincidimos a menudo en los viajes entre Buenos Aires y La Plata, ocupados de funciones profesorales: así fue en 1937, 1938, 1939 y 1940, en que yo iba de visita docente de Chile a la Argentina. En 1941, él me anticipó en el viaje a los Estados Unidos. Creo que es cuando Pedro luce toda su madurez.

No avancemos por los mares de la crítica. A más de riesgosos suelen ser ingratos.

La última vez que nos vimos fue en 1943. Mi postrera aventura docente en Buenos Aires y La Plata, hasta que cayó el bullicioso "peronato". Pedro estaba enflaquecido y pálido. Trabajaba como galeote, corrigiendo pruebas de sus ediciones, redactando prólogos, haciendo notas, dictando clases (de aquí para allá), participando en debates, como si tuviera treinta años y en estado de merecer. Digámoslo con claridad: en la Argentina recibió toda clase de homenajes, salvo uno: el desempeñar a plenitud una cátedra universitaria, por su condición de extranjero que, ya al final, estaba llegando a puerto (la condición de extranjero, no la ciudadanía).

Al despedirme de él, junto al ascensor de su casa, después de haber comido en la dulce paz de su hogar, con los suyos, le pregunté si se sentía mal: “¿Me nota algo?”, me preguntó. Asentí. Entonces me dijo, como quien confiesa algo inconfesable: "La verdad es que hace algún tiempo que no me siento del todo bien..." Se llevó la mano al corazón y agregó: "Este tiene sus picardías". Y, muy bajito: "Pero es un secreto entre usted y yo".

Recordé a González-Prada recatando de su esposa la noticia de un síncope cardíaco. De otro iría a morir ... Este año, conversando con Max y Camila Henríquez Ureña, hermanos de Pedro, pude enterarme de que ellos nada supieron nunca de aquella enfermedad del ausente. Lo entiendo bien ahora.

Cuando murió Pedro, al empinarse a colocar su cartapacio de papeles en una red portaequipaje del tren entre Buenos AiLa Plata, recordé todo aquello. Fue en 1946. Escribí un ar- 
tículo para La Tribuna, de Lima. Desde entonces le estoy debiendo este pequeño Pro-memoria.

Un joven estudioso, Antonio Pagés Larraya, muy bien documentado, formula algunos reparos a la obra de Pedro. No son desatendibles. Pero debieron extenderse al común de los exégetas latinoamericanos. Somos corredores de velocidad; de cortas distancias; ensayistas, no tratadistas; cuentistas antes que novelistas. Conviene ahondar el caso.

Lo primero depende de una causa estrictamente material. Carecemos de profesiones a tiempo completo $\mathrm{y}$, por tanto, a devoción y a paga total. Un hombre debe todavía -y en aquel tiempo era mucho peor- hacer muchas cosas diferentes para subsistir. Pedro Henríquez Ureña, como todos los escritores nuestros, se vio en ese caso. Propongamos aquí una encuesta: los novelistas del siglo XIX fueron permanente o esporádicamente adinerados. Los escritores sin fortuna escriben cuentos, artículos, reseñas, crónicas.

Lo segundo depende de una causa fundamentalmente cultural. Nuestra dotación de hombres preparados era muy pequeña. Por tanto, el que lo estaba debía prestar múltiples servicios. Como los antiguos sacerdotes, debía ser jefe legislativo, político, universitario, literario $\mathrm{y}$, a veces, como Julio Arboleda, Jorge Isaacs, Bartolomé Mitre, Domingo Faustino Sarmiento, Vicente Riva Palacios, etc., también jefe militar. Tantas resposabilidades encogen el ámbito de las posibilidades profundas. Uno se hace fragmentario. La posteridad juzga implacablemente de acuerdo a los resultados, no a las causas o motivos. El desequilibrio es así fatal.

Pedro desempeñó muchas tareas a un mismo tiempo. Fuera de su época como profesor en una Universidad de Minnesota y el de la fugacísima Superintendencia de Educación en la República Dominicana, de que salió asqueado, todo lo suyo fue a corre-vuela, siendo él, sin duda, hombre de sosiego, de ahondamiento, de comprobaciones reiteradas. Su última etapa la pasa como profesor de la Universidad y del Colegio Nacional de La Plata, de la Facultad de Filosofía de Buenos Aires, del Ins- 
tituto de Filología de la Universidad de Buenos Aires, asesor de la Editorial Losada, director de dos colecciones de la misma, conferenciante, redactor de prólogos y artículos, y algo que se me queda por ahí. El crítico que no tome en cuenta semejante, involuntaria e inevitable dispersión, será muy injusto. Pero, al mismo tiempo, la obra que no se resienta de ello, sería mi-lagrosa.

Después de considerarlo no nos asombra que su póstuma Historia de la Cultura en la América Hispánica sea tan esquemática. Debemos quedarnos, como su obra blásica, con $\mathrm{Co}$ rrientes literarias: libro imprescindible.

$*$

Horas de Estudio señala la verdadera aparición de este hombre taciturno y sereno, según sus escrituras; jovial y profuso, según sus pláticas ; intenso y metódico, según sus lecciones. Subtituló el volumen Estudios críticos de filosofía y literatura (París, Ollendorf, 1910). Se advierte ahí el impacto de México sobre el joven socrático, a la sazón de 26 años. Los temas de que se ocupa serán Alfonso Reyes, Antonio Caso, Gabino Barreda; de su patria y aledaños hablará en los trabajos sobre Hostos, Gastón Deligne y "la vida intelectual de Santo Domingo"; revelará sus preocupaciones estilísticas en el estudio sobre el verso endecasílabo; desde luego, rendirá homẹnaje a Rubén Darío, en su apogeo entonces.

Ese mismo año de 1910 publica, en colaboración con Nicolás Rangel, Luis G. Urbina y con el patrocinio de don Justo Sierra, la Antología del Centenario de México, libro no superado todavía.

Pero, ya había asombrado a su coterráneos Pedro con un librito juvenil: Ensayos críticos (Habana, Imp. de E. Fernández, 1905), en el que se ocupó ya de un poeta a quien reiteraría homenaje después: José Joaquín Pérez, a Hostos y a Darío. Interesa este parvo tomo porque en él se recogen las predilecciones juveniles de Pedro: D'Annunzio, Shaw, Wilde, y en música Wagner y Strauss.

Puede afirmarse que, a partir de 1910, y no desde 1905, la vida de Henríquez Ureña está jugada. A cara o cruz: Cruz, 
la enseñanza literaria. No la traiciona, como que ya en 1913 lanza un folleto en México sobre ese tema.

Desde entonces la vida de Pedro transcurre entre lecciones, conferencias, ediciones, debates, traducciones, viajes. Todo eso impidió que el erudito se tragara al hombre de gusto, así como las lecturas evitaron que el viajero se quedase con el profesor.

En 1913, Pedro Henríquez Ureña llama la atención de los críticos literarios de América y España con su prólogo a las obras de don Juan Ruiz de Alarcón (México), donde plantea la tesis de su mexicanismo esencial (hay segunda edición de La Habana, 1915). No es donde se muestra más sereno. Se advierte cierta vehemencia mal contenida, pero se explica no sólo por la edad de Pedro sino también por las circunstancias: la hora cero de la Revolución Mexicana, las resonancias internacionales del suceso mexicano..

Literatura dominicana (París, Revue hispanique, 1917), Antología de la versificación rítmica (San José, Costa Rica, El Convivio, 1918), "El endecasílabo castellano" (Madrid, Revista de Filología, 1919), La versificación en la poesía castellana (Madrid, Revista de Filología, 1920), Observaciones sobre el español en América (Madrid, 1921), los folletos sobre la novela en América (1927), el supuesto andalucismo de nuestro lenguaje, etc.; el ya sesudo volumen Seis ensayos en busca de nuestra expresión (Buenos Aires, Babel, 1928); la estupenda claridad de La cultura y las letras en Santo Domingo (Buenos Aires, 1936); los dos volúmenes de ensayos: Plenitud de América (Buenos Aires, 1952), póstumo, y Plenitud de España (Buenos Aires, 1940) ; todo conduce ya, con más el precioso tesoro de Para la historia de los indigenismos (Buenos Aires, Instituto de Filología, 1938) a la parte final, al opus magna que es Literary Currents in Hispanic America (Cambridge, Mass., Harvard University Press, 1945), traducido póstumamente como Las corrientes literarias en la América Hispánica (México, Fondo de Cultura, 1949).

Pero, al margen de esto, que es lo visible, Pedro Henríquez Ureña dirigió la colección de Cien obras maestras, de la Editorial Losada, y planeó la actual Biblioteca Americana que se publica en México. En realidad, este libro se completa 
con Historia de la cultura en la América Hispánica, también póstumo (México, Fondo de Cultura, 1947).

La obra de Pedro fue así, variada y acezante. Se trasluce en la sequedad de algunos comentarios. Le salvaba su prurito y logro de exactitud. Prolijo y fiel, en él se puede uno confiar, casi siempre, dejando el margen de error humano, indispensable. Uno de ellos fue el que cometió respecto a la novela. Pero, aclaremos: en ese tiempo, nadie pensaba que las leyes de Indias fuesen tan letra muerta respecto de los libros, como en realidad lo fueron.

De ocho partes o capítulos consta Las corrientes literarias... No es un libro de estricta historia literaria, ni de crítica. Participa, como tiene que ser, de los caracteres de crítica, historia, sociología, psicología. Empieza con el descubrimiento del Nuevo Mundo en la imaginación de Europa, y siguen: la creación de una sociedad nueva; el florecimiento del mundo colonial; la declaración de la independencia intelectual; romanticismo y anarquía; el período de organización; literatura pura; problemas de hoy. Me parece que falta un capítulo, no sé si previo o a continuación del primero, sobre el aporte lingüístico, sintético y sensorial del indio. No cabe en capítulo mixto, subsidiariamente. Tal vez, la perspectiva virreinal fuera demasiado amplia, a cambio de una desproporcionada pormenorización de lo más cercano. Discutibles puntos de vista, y, además, mínimos. Nada de eso recorta la dimensión continental, la profundidad de pensamiento, la amplitud de miras con que se mueve Pedro a través de esas páginas realmente magistrales.

Podría afirmarse que, después de leído tal libro, surge con límpidos contornos la imagen de un mundo novomundial. Desde luego, en ello entran ingredientes no siempre igualmente aceptados. Muchos de los que me reprochaban mi "socioliteratura", hace veintitantos años, encontraron justa la posición de Pedro, nada distante casi de la mía, hace quince. Lo digo con afán de prosélito, no de escampavía. Para resal- 
tar cuánto hace la autoridad en aquellos deseosos de tener alguna...

La multiplicidad de tareas obligó a Pedro a un estilo sobrio y cinematográfico. No perdía con ellos la claridad de la frase, ni su estirpe castiza. Sufrió lo que podríamos llamar el regodeo fonético, la suntuosidad. Mas, a fuer de buen gimnasta verbal, había aprendido ese dificilísimo y maduro arte que consiste en decir mucho en poco, la musculosidad de la expresión, exprimida de grasas, tensa y ágil para vencer pruebas ásperas.

De ahí también que lo más jugoso y expresivo de Pedro estuviera en su conversación, en sus clases. Discípulo suyo es hombre -o mujer - herido de su certidumbre. En las pláticas se entregaba. Era un platicante congénito e insuperable. Iba y venía por las ideas y los hechos con una incomparable meticulosidad y, al mismo tiempo, sentido de la perspectiva. Abundaba en citas de memoria, todas oportunas. Los enxiemplos, como en un buen autor árabe, se sucedían en su punto, jugosos, esclarecedores.

De haber sido América un continente menos ardido de vehemencias $\mathrm{y}$ de necesidades primarias, Pedro Henríquez Ureña debió de haber disfrutado de la estupenda prebenda del ocio creador. Lo obligaban a la rapsodia, y él se revolvía gallardo y terco, casi patético contra la coyunda.

Claro, se dirá, no todos nacen con el privilegio de un hogar como el suyo, donde padre, madre, tío, hermanos fueron y son paradigmas de amor a la cultura, recorredores en libros y ciudades de todo lo americano e hispánico. No obstante, muchos que así fueron dotados se descarriaron del camino y prefirieron la pereza a la diligencia, el no hacer nada al trabajar con ahinco por descubrir rutas.

Es nuestro gran ordenador. Los que coincidimos con él en preocupaciones y rumbeos, los que además fuímos y somos como él hombres de andar, ver, oír y leer, comprendemos su cuita. Se nos fue cumplidos los sesenta, con la mente lúcida y la aljaba llena de posibilidades y proyectos. Su maestrazgo vive a través de sus lecciones y colecciones. Para los que le conocimos y disfrutamos del dulce acicate de su nutritiva amistad, Pedro permanece en lo alto de nuestras vi- 
gilias, orientándolas y estimulándolas. Tratar de superarle es arduo, pero la única forma de cumplir con él. Aunque no sea más que en la intención ambiciosa y por tanto creadora.

LUIS ALBERTo SÁNChEZ. Universidad de San Marcos, Lima, Perú. 